\title{
Water, Sanitation, and Hygiene Risk Factors on the Prevalence of Diarrhea among Under-Five Children in the Rural Community of Dangila District, Northwest Ethiopia
}

\author{
Bizuayehu Hailu, ${ }^{1}$ Wu Ji-Guo ${ }^{D},{ }^{1}$ and Tadesse Hailu $\mathbb{D}^{2}$ \\ ${ }^{1}$ Department of Environmental Health, Guangdong Provincial Key Laboratory of Tropical Disease Research, \\ School of Public Health, Southern Medical University, Guangzhou 510515, China \\ ${ }^{2}$ Department of Medical Laboratory Science, College of Medicine and Health Sciences, Bahir Dar University, Bahir Dar, Ethiopia
}

Correspondence should be addressed to Wu Ji-Guo; allanjw@126.com

Received 16 May 2021; Revised 26 July 2021; Accepted 12 August 2021; Published 21 August 2021

Academic Editor: Maoshui Wang

Copyright (c) 2021 Bizuayehu Hailu et al. This is an open access article distributed under the Creative Commons Attribution License, which permits unrestricted use, distribution, and reproduction in any medium, provided the original work is properly cited.

\begin{abstract}
Background. Under-five diarrhea is one of the major causes of morbidity and mortality in developing countries. Despite the tremendous achievement in reducing child mortality and morbidity in the last two decades, diarrhea is still the major causes of morbidity and mortality in resource-limited countries like Ethiopia due to the absence of clean water and poor sanitation and hygiene. Objective. This study aimed to assess the association of water, sanitation, and hygiene on the prevalence of diarrhea among under-five children in the rural community of Ethiopia. Methods. A cross-sectional study was conducted among randomly selected 419 under-five children from October to December 2021 in Dangila district, Northwest Ethiopia. A structured questionnaire was used to collect sociodemographic, environmental, and behavioral data. Data were entered into Epi Info and analyzed using SPSS software. Descriptive analysis was used to calculate the prevalence of diarrhea. Univariate and multivariate logistic regression were used to compute the association of water, sanitation, and hygiene with diarrhea. Statistical significance was considered if $P<0.05$. Results. Among 419 participants, the prevalence of diarrhea was $106(25.3 \%)$. The absence of handwashing habit of children (AOR $=7.70 ; 95 \% \mathrm{CI}: 2.71-21.79)$ and caregivers after toilet (AOR $=19.10 ; 95 \% \mathrm{CI}: 5.46-66.52)$, absence of latrine $(\mathrm{AOR}=3.87$; 95\% CI: $1.24-12.08)$, playing with soil $(\mathrm{AOR}=8.40 ; 95 \% \mathrm{CI}$ : 4.58-36.66), and eating soil $(\mathrm{AOR}=6.24$; $95 \% \mathrm{CI}$ : 1.99-19.78) were significantly associated with under-five diarrhea. Children who drink unprotected water were 2.21 times $(\mathrm{AOR}=2.21 ; 95 \% \mathrm{CI}: 0.51-9.69)$ more exposed to under-five diarrhea than who drink protected water, but it is not statistically significant $(P=0.29)$. Conclusion. The prevalence of under-five diarrhea is high in Dangila district. The absence of clean water and poor handwashing practice and the absence of latrine are the main factors associated with diarrhea. Therefore, strengthening water, sanitation, and hygiene strategy in the rural community should be prioritized.
\end{abstract}

\section{Introduction}

Diarrheal disease remains one of the major causes of mortality and morbidity among under-five children worldwide, especially in sub-Sahara African (SSA) countries which have poor sanitation and hygiene [1]. Diarrheal disease accounts for 1 in 9 child deaths worldwide and around $88 \%$ of the deaths are due to unsafe water, inadequate sanitation, and insufficient hygiene [2]. Diarrheal diseases are the third main cause of illness and death in under-five children in Africa and are accountable for an expected 30 million cases of severe diarrhea and 330,000 deaths in 2015 [3].

Under-five diarrhea is caused by protozoan parasites include Giardia lamblia, Cryptosporidium species, and Entamoeba histolytica [4], bacteria such as Escherichia coli, Salmonella spp., Shigella spp, and Campylobacter jejuni, and rotavirus among the viruses. Of which, rotavirus and E. coli accounted for the most common causes of diarrhea among under-five children $[5,6]$. 
The factors that promote the existence of diarrheal diseases among under-five children are complex, and many of them are related to poor socioeconomic circumstances. The association of poor implementation of water, sanitation, and hygiene (WASH), unsafe human waste disposal, limited access to healthcare education, poor diet, and housing conditions in a community are driving force to under-five diarrhea [7]. These factors play a great role in the transmission of diarrhea-causing pathogen from an infected individual to the healthy one. Unless measure has been taken on the above listed factors, the burden of diarrhea will continue as a problem in a rural community where WASH is poorly practiced.

In Ethiopia, several strategies have been applied to decrease child mortality from under-five diarrhea. The Health Sector Development Program IV (2010/11-2014/15) in the country also aimed to reduce under-five mortality rate from $101 / 1000$ live births to $68 / 1000$. However, child morbidity and mortality in the country remains one of the highest in sub-Saharan Africa [8]. Some studies done in Ethiopia also show that under-five diarrhea is still a core public health problem that kills children, especially in the rural community $[9,10]$. Although proper implementation of WASH reduces the occurrence of under-five diarrhea, it is poorly realized in the rural community of Ethiopia due to lack of awareness. Therefore, the aim of this study was to assess WASH risk factors on the prevalence of under-five diarrhea in Dangila district, Northwest Ethiopia.

\section{Methods}

2.1. Study Design, Area, and Period. A community-based cross-sectional study was conducted among under-five children in Dangila district, Awi zone, Amhara National Regional State, and Northwest Ethiopia from October to December 2020. Dangila is found in the north of Ethiopia $\left(11^{\circ} 16^{\prime} \mathrm{N} 36^{\circ} 50^{\prime} \mathrm{E}\right)$ with an altitude of 2,137 meters above the sea level, $21^{\circ} \mathrm{C}$ mean annual temperature, and 1,260.7 millimeters mean annual rainfall.

All children aged 6 months to less than 5 years and lived in the study area for 3 months prior to data collection and their parents who were volunteered, gave consent, and filled the questionnaire during the data collection time were included in the study. Mothers/fathers of the selected children unable to respond to the questionnaire and critically ill during data collection were excluded from the study.

The sample size was calculated by single population proportion formula using 50\% prevalence of diarrhea, 95\% confidence level $(Z=1.96)$, and $5 \%$ margin of error $(d=0.05)$ because there is no previous study conducted in the study area $[11]$.

$$
\begin{aligned}
& n=\frac{Z_{a / 2}^{2} \cdot P(1-P)}{d^{2}}, \\
& n=\frac{(1.96) 2(0.50)(0.50)}{(0.05) 2}=384 .
\end{aligned}
$$

By considering a $10 \%$ (38) nonresponse rate, the final sample size was $422(384+38)$.
2.2. Sampling Techniques. Among 30 kebeles, the smallest administrative units of districts in Dangila district, 15 kebeles (Abadira, Agaga, Chara, Dengeshita, Dimsa, Dube, Gisa, Gult, Gumdery, Manguda, Muksy, Quandisha, Quancha, Wufta, and Zelesa kebeles) were randomly selected and included in the study. Those households which had under-five children were screened and listed using a family folder at health posts based on the community-based information system. Then, households with under-five children were selected with a systematic random sampling technique. The number of under-five children in each Kebele was proportionally allocated from the total number of households which have under-five children in 15 selected kebeles. A systematic random sampling technique was used to select the households that have under-five children in each kebele. For those households with more than one under-five children, only one child was selected by the lottery method to be a part of the study.

\subsection{Data Collection Techniques}

2.3.1. Questionnaire. A structured questionnaire was used to collect socio-demographic, health status of the under-five children and WASH-related data from mothers/fathers of under-five children through face-to-face interview and observational checklist. At the time of interview, children finger nails status (whether trimmed or not) and children shoes wearing status (whether wore or not) were checked. Questionnaires were filled by trained 4 nurses and supervised by two health officers.

2.4. Quality Control. Training was given for data collectors and supervisors prior to data collection. Pretest was conducted (in Wondefay kebele which is not included as a study kebele in Dangila district) to check whether respondents interpreting questions correctly and the order of the questions is not affecting the respondents answers by using $5 \%$ of the total sample sizes (nearly 22 participants) to standardize the questionnaires, data collection, and data processing. Identified problems during pretest were corrected before the start of actual data collection. Filled data questionnaires were cross-checked by the supervisors for their completeness, consistency, and accuracy. Generally, the reliability of data was assured during preanalytical, analytical, and postanalytical quality control steps.

2.5. Data Management and Analysis. Data were cleaned and entered into Epi Info version 6.04 and analyzed using Statistical Package for Social Sciences (SPSS) version 25 statistical software. The prevalence of diarrhea among under-five children was calculated by descriptive statistics. Univariate logistic regression was used to assess WASHrelated factors associated with under-five children diarrhea. To resolve the confounding effect, variables with $P<0.25$ in the univariate logistic regression were further analyzed by multivariate logistic regression analysis 95\% confidence 
interval (CI). Variables with $P<0.05$ in the multivariate analysis were considered as statistically significant.

2.6. Ethical Considerations. This study was ethically approved by Institutional Ethical Review Committee of Southern Medical University, School of international education, Department of Public Health. Supportive letter was obtained from Amhara Public Health Institute, Awi zone health office, and Dangila districts health office. Permission letters were secured from selected kebeles administrative offices. The purpose of the study was clearly explained to all parents of study participants before obtaining a written informed consent. All under-five children who had diarrhea during the data collection time were consulted to be taken to clinic and visited a doctor.

\section{Results}

3.1. Sociodemographic Characteristics of the Study Participants. From the total 422, 419 under-five children were participated in this study with $3(0.7 \%)$ nonrespondent rates of their parents. The mean age of the study participants were 2.33 years, ranged from 0 to 4 years with standard deviation 1.11 years. The distribution of the study participants was higher $(220(52.5 \%))$ in the age group of 0 to 2 years. The majority of children parents' educational statuses were able to read and write $(202(48.2 \%))$, married (387 $(92.4 \%)$ ), and monthly income less than 11.33 USD (254 $(60.6 \%))$. The majority of under-5-year children (272 (64.9\%)) were found in the family size of 5 to 9 (Table 1 ).

3.2. The Prevalence of Diarrhea in the Selected Kebeles. The total prevalence of diarrhea was 106 (25.3\%; 95\% CI: 22.2-29.8). Among the selected kebeles, the prevalence of diarrhea was higher $(9(29 \%))$ in Dimsa followed by Agaga ( 8 $(28.6 \%))$ and Wufta $(8(28.6 \%))$ kebeles. Lower prevalence rate of diarrhea was recorded in Zelesa (5 (18.5\%)), Quancha (6 (21.3\%)), and Dube (7 (22.8\%)) kebeles (Table 2).

3.3. Diarrhea and Other Health Complications of Under-Five Children. The prevalence rates of diarrhea $56.6 \%(60 / 106)$ among females and $60.4 \%(64 / 106)$ in the age group of 0 to 2 years was higher than the respective males $43.4 \%(46 / 106)$ and $39.6 \%(42 / 106)$ in the age group of 3 to 4 years. The prevalence of loss of appetite among under-five children was $28.9 \%(121 / 419)$ which accounted for high prevalence $(59.5 \%$ (72/121)) among females and $(61.2 \%(74 / 121))$ in the 0 - to 2 year age groups. The prevalence of sense of tiredness among the study was $(32.5 \%(136 / 419))$ which was highly prevalent among female participants $(52.9 \%(72 / 136))$ and in the age group of 0 to 2 years $(58.1 \%$ (79/136)). Under-five children who had vomiting accounted for $(42.0 \%(176 / 419))$. Of which, high vomiting was reported among males (52.8\% (93/ $176))$ and in the age group of 0 to 2 years $(52.3 \%(92 / 176))$. The prevalence of abdominal pain in under-5-year children was $32.2 \%(135 / 419)$ which accounted for $(53.3 \%(72 / 135))$
TABle 1: Sociodemographic characteristics of the under-five children and their parents in Dangila district, Northwest Ethiopia, $2021(N=419)$

\begin{tabular}{|c|c|c|c|}
\hline Variables & & Number & Percentage \\
\hline \multirow{2}{*}{ Age in years } & $0-2$ & 220 & 52.5 \\
\hline & $3-4$ & 199 & 47.5 \\
\hline \multirow{2}{*}{ Sex } & $\mathrm{M}$ & 212 & 50.6 \\
\hline & $\mathrm{F}$ & 207 & 49.4 \\
\hline \multirow{6}{*}{ Father educational status } & Illiterate & 163 & 38.9 \\
\hline & Read and write & 202 & 48.2 \\
\hline & Primary & 30 & 7.2 \\
\hline & Junior & 19 & 4.5 \\
\hline & High school & 0 & 0 \\
\hline & College & 5 & 1.2 \\
\hline \multirow{6}{*}{$\begin{array}{l}\text { Mothers educational } \\
\text { status }\end{array}$} & Illiterate & 154 & 36.8 \\
\hline & Read and write & 202 & 48.2 \\
\hline & Primary & 32 & 7.6 \\
\hline & Junior & 27 & 6.4 \\
\hline & High school & 0 & 0.0 \\
\hline & College & 4 & 1.0 \\
\hline \multirow{3}{*}{ Marital status of parents } & Married & 387 & 92.4 \\
\hline & Divorce & 14 & 3.3 \\
\hline & Widowed & 18 & 4.3 \\
\hline \multirow{3}{*}{ Monthly income in USD } & $<11.33$ & 254 & 60.6 \\
\hline & $11.33-22.66$ & 142 & 33.9 \\
\hline & $>22.66$ & 23 & 5.5 \\
\hline \multirow{2}{*}{ Family size } & $2-4$ & 147 & 35.1 \\
\hline & $5-9$ & 272 & 64.9 \\
\hline
\end{tabular}

TABLe 2: The distribution of under-five children across their prevalence of diarrhea in the selected kebeles of Dangla district, Northwest Ethiopia, $2021(N=419)$.

\begin{tabular}{lccc}
\hline \multirow{2}{*}{ Name of kebeles } & \multicolumn{3}{c}{ Diarrhea status of under-five children } \\
& No, $n(\%)$ & Yes, $n(\%)$ & Total, $n(\%)$ \\
\hline Abadira & $24(72.7)$ & $9(27.3)$ & $33(8.0)$ \\
Agaga & $20(71.4)$ & $8(28.6)$ & $28(6.7)$ \\
Chara & $9(75)$ & $3(25)$ & $12(3.0)$ \\
Dengeshita & $22(73.3)$ & $8(26.7)$ & $30(7.2)$ \\
Dimsa & $22(70.9)$ & $9(29)$ & $31(7.1)$ \\
Dube & $24(77.4)$ & $7(22.6)$ & $31(7.4)$ \\
Gisa & $24(72.7)$ & $9(27.3)$ & $33(7.9)$ \\
Gult & $23(74.2)$ & $8(25.8)$ & $31(7.4)$ \\
Gumdery & $17(77.3)$ & $5(22.7)$ & $22(5.3)$ \\
Manguda & $23(74.2)$ & $8(25.8)$ & $31(7.4)$ \\
Muksy & $21(75)$ & $7(25)$ & $28(6.7)$ \\
Quandisha & $20(76.9)$ & $6(23.1)$ & $26(6.2)$ \\
Quancha & $22(78.6)$ & $6(21.3)$ & $28(6.7)$ \\
Wufta & $20(71.4)$ & $8(28.6)$ & $28(6.7)$ \\
Zelesa & $22(81.5)$ & $5(18.5)$ & $27(6.4)$ \\
Total & $313(74.7)$ & $106(25.3)$ & $419(100)$ \\
\hline
\end{tabular}

prevalence among females and $(55.6 \%(75 / 135))$ in the age group of 0 to 2 years (Table 3 ).

3.4. Prevalence of Diarrhea and WASH Indicators among Under-Five Children. High prevalence rate of diarrhea was obtained among under-five children who did not wash 
hands before their meal $(49(72.1 \%))$, practiced open defecation (48 $(33.8 \%))$, drank river water sources (14 $(53.3 \%))$, and caregivers who did not wash hand before feeding under-five children (52 (76.5\%)) (Table 4). Diarrhea was also high among under-five children who live in unclean environment $(38(84.4 \%))$, a house with no handwashing facilities $(90(37.5 \%))$, no solid waste disposal facilities $(63(53.3 \%))$, and no liquid waste disposal facilities $(80(51.3 \%))$ (Table 4$)$.

3.5. Factors Associated with Under-Five Diarrhea. In the univariate logistic regression analysis, the presence of two under-five children per house, family size less than five, going to latrine with barefoot, playing with soil, eating soil, eating fruits and vegetable, having close contact with pets, absence of handwashing habit before meal and after toilet, having open defecation practice, no handwashing practice of caregivers, untrimmed nail status, drinking unprotected water source, and family monthly income less than 11.33 USD were associated $(P<0.01)$ with under-five diarrhea (Table 5).

In the multivariate logistic regression analysis, underfive children who play with soil were 8.40 times $(\mathrm{AOR}=8.40 ; 95 \% \mathrm{CI}: 4.58-36.66)$ more at risk than under-five children who did not play with soil. The habit of eating soil increases the odds of diarrheal infection by 6.28-fold $(\mathrm{AOR}=6.24 ; 95 \% \mathrm{CI}$ : 1.99-19.78) higher than under-five children who did not eat soil. Children who have close contact with pets were 4.73 times $(\mathrm{AOR}=4.73$; 95\% CI: 1.78-12.59) more exposed to diarrhea disease than those who did not have close contact with pets. Under-five children who do not wash their hand after latrine were 7.70 times ( $\mathrm{AOR}=7.70 ; 95 \% \mathrm{CI}$ : 2.71-21.79) more at risk than under-five children who washed their hand after toilet. The habit of caregiver not washing their hand before feeding their children increases the odds of under-five children diarrhea by 19.10-fold (AOR = 19.10; 95\% CI: 5.46-66.52) higher than their counterparts. Under-five children who live in households which do not have latrine were 3.87 times $(\mathrm{AOR}=3.87: 95 \% \mathrm{CI}$ : 1.24-12.08) more at risk than under-five children live a household which have latrine. Children whose parents have monthly income less than 11.33 USD were 2.90 times $(\mathrm{AOR}=2.90 ; 95 \% \mathrm{CI}: 1.04-8.08)$ more at risk to diarrhea than whose parents' monthly income is greater than 11.33 USD (Table 5).

\section{Discussion}

Diarrhea among under-five children is a common problem in developing countries, especially in the rural area, due to sanitation problem and predisposing environmental factors [12]. In this study, the total prevalence of diarrhea was $25.3 \%$ (95\% CI: $22.2 \%-29.7 \%$ ) which is higher than previous prevalence reports $10.77 \%$ in rural community of Enugu, South East Nigeria [13], and 22.1\% in rural area of north Gondar, Ethiopia [12]. But it is lower than 29.9\% in north central Ethiopia [14], and $32.6 \%$ in rural Burundi [15]. The difference might be due to the variation in the time period of data collection, socio-demographic characteristics of the study subjects, the sanitation and hygiene practice, the educational level of parents in the household level and study periods. The other justification might be only active cases of diarrhea were collected in this study.

In this study, higher prevalence of diarrhea (60.4\%) was obtained in the age group of 0 to 2 years. This finding is consistent with earlier reports conducted in rural area of north Gondar [12]. The possible justification to lower age group might be the low level of immunity in lower ages of under-five children, high risk of eating contaminated foods and drinks, crawling starting time of kids, high contamination rate of hands of kids, and low sanitation practices.

The distribution of under-five diarrhea among households with no clean environment was $84.4 \%$ in this study. This result is supported by a previous report which shows children who live in a clean surrounding are less likely to be exposed to under-five diarrhea [16]. The possible justification might be open defecation is a common problem in rural area, and contaminated environment is a potential source of diarrhea-causing pathogens.

The absence of handwashing facility accounted for high prevalence of diarrhea (37.5\%) in this study $(P \leq 0.001)$. This finding was supported by a previous report the presence of handwashing facility decreases the prevalence of under-five diarrhea in a rural community [12]. This could be justified as the knowledge of washing hands before eating in under-five children is low, especially in rural areas.

Good waste management system in a community helps to minimize diarrhea among children. The prevalence of diarrhea among households with no liquid waste disposal (51.3\%) with $(P \leq 0.001)$ and no solid waste disposal $(53.3 \%)$ with $(P \leq 0.001)$ were high in this study. This result is consistent with an earlier report that shows improper liquid and solid waste disposal is associated with under-five diarrhea [17]. This is possible that poor liquid and solid waste management can easily contaminate the soil where kids are playing.

In this study, under-five children having ingesting soil habit were significantly associated $(P=0.002)$ with underfive children diarrhea. This result is consistent with previous reports $[18,19]$. Playing with soil was also significantly associated $(P \leq 0.001)$ with under-five diarrhea, which is similar with previous study [20]. The possible explanation could be that soil is a potential source of pathogens that cause under-five children diarrhea, especially in rural area where eating soil and eating food with contaminated hands is a common phenomenon. Another explanation might be playing on the ground by making borehole-a type of game played by kids on the ground which contaminates the hands of children with soil which might contain pathogen.

Some diarrhea-causing pathogens can be transmitted by close contact with animals [21]. In this study, under-five children who have close contact with pets were significantly associated $(P=0.002)$ with under-five children diarrhea. This result was similar to an earlier report [22]. The current report is also supported by previous report, close contact with domestic animals increases diarrhea among children 
TABle 3: Prevalence of diarrhea and other health complications of under-five children across their age and sex in Dangila district, Northwest Ethiopia, $2021(N=419)$.

\begin{tabular}{|c|c|c|c|c|c|c|c|c|c|c|}
\hline \multirow{3}{*}{ Variables of health complications } & \multicolumn{4}{|c|}{$\operatorname{Sex}(n)$} & \multicolumn{6}{|c|}{ Age in years $(n)$} \\
\hline & \multicolumn{2}{|c|}{ M } & \multicolumn{2}{|c|}{$\mathrm{F}$} & \multicolumn{2}{|c|}{$0-2$} & \multicolumn{2}{|c|}{$3-5$} & \multicolumn{2}{|c|}{ Total } \\
\hline & Yes & No & Yes & No & Yes & No & Yes & No & Yes & No \\
\hline Diarrhea & 46 & 166 & 60 & 147 & 64 & 156 & 42 & 157 & 106 & 313 \\
\hline Loss of appetite & 49 & 163 & 72 & 135 & 74 & 146 & 47 & 152 & 121 & 298 \\
\hline Sense of tired & 64 & 148 & 72 & 135 & 79 & 141 & 57 & 142 & 136 & 283 \\
\hline Vomiting & 93 & 119 & 83 & 124 & 92 & 128 & 84 & 115 & 176 & 243 \\
\hline Abdominal pain & 63 & 149 & 72 & 135 & 75 & 145 & 60 & 139 & 135 & 284 \\
\hline
\end{tabular}

TABle 4: Status of under-five diarrhea across WASH indicators among children in Dangila district, Northwest Ethiopia, 2021 (N=419).

\begin{tabular}{|c|c|c|c|c|c|}
\hline \multirow{2}{*}{ WASH indicators } & & \multicolumn{3}{|c|}{ Status of under-five diarrhea } & \multirow{2}{*}{$\chi^{2}, P$ value } \\
\hline & & Yes, $n(\%)$ & No, $n(\%)$ & Total, $n(\%)$ & \\
\hline \multirow{2}{*}{ Under-five children handwashing practice before their meal } & Yes & $57(16.2)$ & $294(83.8)$ & $351(83.8)$ & \multirow{2}{*}{$93.92, \leq 0.001$} \\
\hline & No & $49(72.1)$ & $19(27.9)$ & $68(16.2)$ & \\
\hline \multirow{2}{*}{ Open defecation practice of under-five children } & No & $58(20.8)$ & $221(79.2)$ & $279(66.6)$ & \multirow{2}{*}{$8.99,0.002$} \\
\hline & Yes & $48(33.8)$ & $92(64.8)$ & $142(33.4)$ & \\
\hline \multirow{2}{*}{ Caregiver hand wash practice before feeding their under-five children } & Yes & $54(15.4)$ & $297(84.6)$ & $351(83.8)$ & \multirow{2}{*}{$112.48, \leq 0.001$} \\
\hline & No & $52(76.5)$ & $16(23.5)$ & $68(16.2)$ & \\
\hline \multirow{4}{*}{ Drinking water source of under-five children } & River & $14(53.3)$ & $10(41.7)$ & $24(5.7)$ & \multirow{4}{*}{$15.44,0.001$} \\
\hline & Stream & $7(25)$ & $21(75)$ & $28(6.7)$ & \\
\hline & Well & $32(25.8)$ & $92(74.2)$ & $124(29.6)$ & \\
\hline & Tape & $53(21.8)$ & $190(78.3)$ & $243(58)$ & \\
\hline \multirow{2}{*}{ Presence of clean environment } & Yes & $68(18.2)$ & $306(81.8)$ & $374(89.3)$ & \multirow{2}{*}{$93.32, \leq 0.001$} \\
\hline & No & $38(84.4)$ & $7(15.6)$ & $45(10.7)$ & \\
\hline \multirow{2}{*}{ Handwashing facility } & Present & $16(8.9)$ & $163(91.1)$ & $179(42.7)$ & \multirow{2}{*}{$44.26, \leq 0.001$} \\
\hline & Absent & $90(37.5)$ & $150(62.5)$ & $240(57.8)$ & \\
\hline \multirow{2}{*}{ Solid waste disposal } & Present & $43(13.8)$ & $268(86.2)$ & $311(74.2)$ & \multirow{2}{*}{$84.02, \leq 0.001$} \\
\hline & Absent & $63(53.3)$ & $45(41.2)$ & $108(25.8)$ & \\
\hline \multirow{2}{*}{ Liquid waste disposal } & Present & $26(9.9)$ & $237(90.1)$ & $263(62.8)$ & \multirow{2}{*}{$88.79, \leq 0.001$} \\
\hline & Absent & $80(51.3)$ & $76(48.7)$ & $156(37.2)$ & \\
\hline
\end{tabular}

TABLE 5: Bivariate and multivariate analysis of factors associated with diarrhea among under-five children in Dangila district, Northwest Ethiopia, $2021(N=419)$.

\begin{tabular}{|c|c|c|c|c|c|c|c|}
\hline \multirow{2}{*}{ Variables } & & \multicolumn{2}{|c|}{ Diarrhea } & \multirow{2}{*}{ COR $(95 \% \mathrm{CI})$} & \multirow{2}{*}{$P$ value } & \multirow{2}{*}{ AOR $(95 \% \mathrm{CI})$} & \multirow{2}{*}{$P$ value } \\
\hline & & Yes & No & & & & \\
\hline \multirow{2}{*}{ Number of $<5$ children/house } & Two & 40 & 21 & $8.43(4.66-15.23)$ & \multirow{2}{*}{$\leq 0.001$} & \multirow{2}{*}{$1.62(0.47-5.63)$} & \multirow{2}{*}{0.447} \\
\hline & One & 66 & 292 & 1 & & & \\
\hline \multirow{2}{*}{ Family size } & $\geq 5$ & 21 & 31 & $2.25(1.23-4.11)$ & \multirow{2}{*}{0.009} & \multirow{2}{*}{$2.45(0.74-8.39)$} & \multirow{2}{*}{0.139} \\
\hline & $<5$ & 85 & 282 & 1 & & & \\
\hline \multirow{2}{*}{ Going to latrine with barefoot } & Yes & 51 & 41 & $6.15(3.72-10.17)$ & \multirow{2}{*}{$\leq 0.001$} & \multirow{2}{*}{$2.45(0.84-7.13)$} & \multirow{2}{*}{0.100} \\
\hline & No & 55 & 272 & 1 & & & \\
\hline \multirow{2}{*}{ Playing with soil } & Yes & 82 & 86 & $9.02(5.37-15.14)$ & \multirow{2}{*}{$\leq 0.001$} & \multirow{2}{*}{$8.40(4.58-36.66)$} & \multirow{2}{*}{$\leq 0.001$} \\
\hline & No & 24 & 227 & 1 & & & \\
\hline \multirow{2}{*}{ Eating soil } & Yes & 51 & 30 & $8.75(5.12-14.94)$ & \multirow{2}{*}{$\leq 0.001$} & \multirow{2}{*}{$6.28(1.99-19.78)$} & \multirow{2}{*}{0.002} \\
\hline & No & 55 & 283 & 1 & & & \\
\hline \multirow{2}{*}{ Eating fruits and vegetable } & Yes & 35 & 43 & $3.10(1.85-5.19)$ & \multirow{2}{*}{$\leq 0.001$} & \multirow{2}{*}{$1.99(0.69-5.76)$} & \multirow{2}{*}{0.207} \\
\hline & No & 71 & 270 & 1 & & & \\
\hline \multirow{2}{*}{ Having close contact with pets } & Yes & 82 & 37 & $25.49(14.42-45.06)$ & \multirow{2}{*}{$\leq 0.001$} & \multirow{2}{*}{$4.73(1.78-12.59)$} & \multirow{2}{*}{0.002} \\
\hline & No & 24 & 276 & 1 & & & \\
\hline \multirow{2}{*}{ Hand wash habit before meal } & Yes & 92 & 298 & 1 & \multirow{2}{*}{0.005} & $159(033-760)$ & 0559 \\
\hline & No & 14 & 15 & $3.02(1.41-6.50)$ & & $1.59(0.33-7.60)$ & 0.559 \\
\hline
\end{tabular}


TABLE 5: Continued.

\begin{tabular}{|c|c|c|c|c|c|c|c|}
\hline \multirow{2}{*}{ Variables } & & \multicolumn{2}{|c|}{ Diarrhea } & \multirow{2}{*}{ COR $(95 \% \mathrm{CI})$} & \multirow{2}{*}{$P$ value } & \multirow{2}{*}{ AOR (95\% CI) } & \multirow{2}{*}{$P$ value } \\
\hline & & Yes & No & & & & \\
\hline \multirow{2}{*}{ Handwashing habit after toilet } & Yes & 116 & 241 & 1 & \multirow{2}{*}{$\leq 0.001$} & \multirow{2}{*}{$7.70(2.71-21.79)$} & \multirow{2}{*}{$\leq 0.001$} \\
\hline & No & 90 & 72 & $18.83(10.40-34.08)$ & & & \\
\hline \multirow{2}{*}{ Having open defecation practice of kids } & Yes & 48 & 92 & $1.99(1.26-3.13)$ & \multirow{2}{*}{0.003} & \multirow{2}{*}{$1.06(0.40-2.81)$} & \multirow{2}{*}{0.903} \\
\hline & No & 58 & 221 & 1 & & & \\
\hline \multirow{2}{*}{ Care giver handwashing habit } & Yes & 54 & 297 & 1 & \multirow{2}{*}{$\leq 0.001$} & \multirow{2}{*}{$19.10(5.46-66.52)$} & \multirow{2}{*}{$\leq 0.001$} \\
\hline & No & 52 & 16 & $17.88(9.51-33.59)$ & & & \\
\hline \multirow{2}{*}{ Kids nail status } & Trimmed & 69 & 268 & 1 & \multirow{2}{*}{0.001} & \multirow{2}{*}{$2.76(0.90-8.50)$} & \multirow{2}{*}{0.076} \\
\hline & Untrimmed & 37 & 45 & $4.49(2.45-8.22)$ & & & \\
\hline \multirow{2}{*}{ Presence of latrine } & Yes & 57 & 294 & 1 & \multirow{2}{*}{0.001} & \multirow{2}{*}{$3.87(1.24-12.08)$} & \multirow{2}{*}{0.020} \\
\hline & No & 49 & 19 & $13.03(7.29-24.26)$ & & & \\
\hline \multirow{2}{*}{ Drinking water source } & Unprotected & 21 & 31 & $2.25(1.23-4.11)$ & \multirow{2}{*}{0.009} & \multirow{2}{*}{$2.21(0.51-9.69)$} & \multirow{2}{*}{0.290} \\
\hline & Protected & 85 & 282 & 1 & & & \\
\hline \multirow{2}{*}{ Family monthly income in USD } & $<11.33$ & 79 & 175 & $2.31(1.41-3.77)$ & \multirow{2}{*}{0.001} & \multirow{2}{*}{$2.90(1.04-8.08)$} & \multirow{2}{*}{0.042} \\
\hline & $\geq 11.33$ & 27 & 138 & 1 & & & \\
\hline
\end{tabular}

[23]. This could be justified as zoonotic transmission of pathogens by close contact with domestic animals, including livestock, poultry, and companion animals, has been shown to play a role in the epidemiology and transmission of diarrhea-causing pathogens [21].

Good handwashing practices deceases the prevalence of diarrhea-causing pathogens. In this study, the habit of under-five children not to wash hands after toilet was significantly associated $(P \leq 0.001)$ with under-five diarrhea. Similar finding is obtained from a previous study [22]. In the same way, caregivers who do not wash hands before feeding their kids were also significantly associated $(P \leq 0.001)$ with under-five diarrhea, which is consistent with previous report [16]. This can be justified as children or their parents may go to latrine and feed without washing their hands which leads to the transmission of diarrhea-causing pathogens.

The absence of latrine in this study was significantly associated $(P=0.020)$ with under-five diarrhea. This result is consistent with a previous report which shows that the availability of a latrine in the house decreases the prevalence of diarrhea [16]. This might be because improper utilization of latrine does not bury feces that contain diarrhea-causing pathogens.

Under-five children drinking unprotected (river and/or stream) water source were 2.21 times more at risk than those who drink protected (Tape and/or well) water source, but not statistically significant $(P=0.290)$. This result is similar to previous study report [24]. This can be justified most water sources for animals and humans in the rural area are rivers which can be easily contaminated with human and animal excreta.

4.1. Limitation of the Study. Using a cross-sectional study design is one of the limitations for this study.

\section{Conclusion}

The prevalence of under-five diarrhea is high in Dangila district. WASH is also poorly implemented in the Dangila district. Poor handwashing habit of children and caregivers after toilet, absence of latrine, eating and play with soil, having close contact with pets, and family monthly income less than 11.33 USD are significantly associated with under-five diarrhea. Therefore, strengthening availability of clean water, effective sanitation, and hygiene strategy in the rural community should be prioritized to minimize the prevalence of under-five diarrhea. And also further studies with large sample size and study area should be done.

\section{Data Availability}

Data are available in any open databases without limit including the Bahir Dar University website (https://bdu.edu. et/node/74).

\section{Conflicts of Interest}

The authors declare that they have no conflicts of interest.

\section{Acknowledgments}

The authors acknowledge the health extension workers in the selected kebeles and the parents of the study participants in this study.

\section{References}

[1] T. Z. Aklilu and A. A. Zewdie, "Determinants of under-five childhood diarrhea in kotebe health center, yeka sub city, Addis Ababa, Ethiopia: a case control study," Global Journal of Medical Research, vol. 14, no. 4, 2014.

[2] Center for Disease Control and Prevention, "Diarrhea (CDC). Common illness, global killer," 2020, https://www.cdc.gov/ healthywater/pdf/global/programs/globaldiarrhea508c.pdf.

[3] R. C. Reiner, N. Graetz, D. C. Casey et al., "Variation in childhood diarrheal morbidity and mortality in Africa, 2000-2015," New England Journal of Medicine, vol. 379, pp. 1128-1138, 2018. 
[4] A. Efstratiou, J. E. Ongerth, and P. Karanis, "Waterborne transmission of protozoan parasites: review of worldwide outbreaks-an update 2011-2016," Water Research, vol. 114, pp. 14-22, 2017.

[5] T. V. Nguyen, L. P. Van, L. C. Huy, N. K. Gia, and A. Weintraub, "Etiology and epidemiology of diarrhoea in children in Hanoi, Vietnam," International Journal of Infectious Diseases, vol. 10, pp. 298-308, 2006.

[6] A. Saeed, H. Abd, and G. Sandstrom, "Microbial aetiology of acute diarrhoea in children under five years of age in Khartoum, Sudan," Journal of Medical Microbiology, vol. 64, no. Pt 4, pp. 432-437, 2015.

[7] L. Carvajal-Vélez, A. Amouzou, J. Perin et al., "Diarrhea management in children under five in sub-saharan Africa: does the source of care matter? a countdown analysis," $B M C$ Public Health, vol. 16, p. 830, 2016.

[8] Federal Ministry of Health of Ethiopia (FMOH), "Health sector development program IV. Addis ababa: federal ministry of health of Ethiopia," 2013, https://www.ccghr.ca/wpcontent/uploads/2013/11/healthsectordevelopmentprogram. pdf.

[9] H. Abdiwahab, K. Abera, and G. Janvier, "Hand washing with soap and WASH educational intervention reduces under-five childhood diarrhoea incidence in Jigjiga district, eastern Ethiopia: a community-based cluster randomized controlled trial," Preventive Medicine Reports, vol. 6, pp. 361-368, 2017.

[10] A. Bayeh, H. Tadesse, B. Laway, M. Wondemagegn, Y. Endalew, and K. Mulugeta, "Aetiology of acute diarrhoea and antimicrobial usage among children aged under five years at health centres in Bahir Dar, Ethiopia," Tropical Doctor, vol. 50, no. 3, pp. 190-194, 2020.

[11] L. Naing, T. Winn, and B. N. Rusli, "Practical issues in calculating the sample size for prevalence studies," Archives of Orofacial Sciences, vol. 1, pp. 9-14, 2006.

[12] A. Getachew, A. Tadie, M. G. Hiwot et al., "Environmental factors of diarrhea prevalence among under five children in rural area of north Gondar zone, Ethiopia," Italian Journals of Pediatrics, vol. 44, p. 95, 2018.

[13] U. U. Nwokoro, O. Ugwa, C. D. Onwuliri, I. F. Obi, M. O. Ngozi, and C. Agunwa, "Water, sanitation and hygiene risk factors associated with diarrhoea morbidity in a rural community of Enugu, south east Nigeria. Pan African," Medical Journal, vol. 37, p. 115, 2020.

[14] Y. Tafere, B. A. Abate, H. D. Enyew, and A. B. Kekkonen, "Diarrheal diseases in under-five children and associated factors among Farta district rural community, Amhara regional state, north central Ethiopia: a comparative crosssectional study," Journal of Environmental and Public Health, vol. 2020, Article ID 6027079, 7 pages, 2020.

[15] K. Diouf, P. Tabatabai, J. Rudolph, and M. Marx, "Diarrhoea prevalence in children under five years of age in rural Burundi: an assessment of social and behavioural factors at the household level," Global Health Action, vol. 7, p. 24895, 2014.

[16] E. B. Oloruntoba, T. Folarin, and A. I. Ayede, "Hygiene and sanitation risk factors of diarrhoeal disease among under-five children in Ibadan, Nigeria," African Health Sciences, vol. 14, no. 4, pp. 1001-1011, 2014.

[17] A. M. Ayalew, W. T. Mekonnen, S. W. Abaya, and Z. A. Mekonnen, "Assessment of diarrhea and its associated factors in under-five children among open defecation and open defecation-free rural settings of Dangla district, northwest Ethiopia," Journal of Environmental and Public Health, vol. 2018, Article ID 4271915, 8 pages, 2018.
[18] W. A. Shivoga and W. N. Moturi, "Geophagia as a risk factor for diarrhoea," Journal of Infection in Developing Countries, vol. 3, no. 2, pp. 94-98, 2009.

[19] V. Bauza, R. M. Ocharo, T. H. Nguyen, and J. S. Guest, "Soil ingestion is associated with child diarrhea in an urban slum of Nairobi, Kenya," The American Journal of Tropical Medicine and Hygiene, vol. 96, no. 3, pp. 569-575, 2017.

[20] A. G. Wasihun, T. A. Dejene, M. Teferi et al., "Risk factors for diarrhoea and malnutrition among children under the age of 5 years in the Tigray region of northern Ethiopia," PLoS One, vol. 13, no. 11, Article ID e0207743, 2018.

[21] N. Steinmuller, L. Demma, J. B. Bender, M. Eidson, and F. J. Angulo, "Outbreaks of enteric disease associated with animal contact: not just a foodborne problem anymore," Clinical Infectious Diseases, vol. 43, no. 12, pp. 1596-1602, 2006.

[22] S. Omona, G. M. Malinga, R. Opoke, G. Openy, and R. Opiro, "Prevalence of diarrhoea and associated risk factors among children under five years old in Pader district, northern Uganda," BMC Infectious Diseases, vol. 20, p. 37, 2020.

[23] A. Conan, C. O’Reilly, E. Ogola et al., "Animalrelated factors associated with moderate-to-severe diarrhea in children younger than five years in western Kenya: a matched casecontrol study," PLoS Neglected Tropical Diseases, vol. 11, no. 8, Article ID e0005795, 2017.

[24] T. A. Gashaw and Y. M. Walie, "Prevalence and determinate factors of diarrhea morbidity among under five children in Shake zone, southwest Ethiopia, a community based crosssectional study," Arch Community Med Public Health, vol. 5, no. 1, pp. 008-014, 2019. 